\title{
Accidents and opportunities: a history of the radio echo-sounding of Antarctica, 1958-79
}

\author{
SIMONE TURCHETTI, KATRINA DEAN, SIMON NAYLOR \\ AND MARTIN SIEGERT*
}

\begin{abstract}
This paper explores the history of radio echo-sounding (RES), a technique of glaciological surveying that from the late 1960s has been used to examine Antarctica's sub-glacial morphology. Although the origins of RES can be traced back to two accidental findings, its development relied upon the establishment of new geopolitical conditions, which in the 1960s typified Antarctica as a continent devoted to scientific exploration. These conditions extended the influence of prominent glaciologists promoting RES and helped them gather sufficient support to test its efficiency. The organization and implementation of a large-scale research programme of RES in Antarctica followed these developments. The paper also examines the deployment of RES in Antarctic explorations, showing that its completion depended on the availability of technological systems of which RES was an integral part.
\end{abstract}

The publication of Antarctica's Glaciological and Geophysical Folio in 1983 revealed the dimensions of the ice sheet that covers a large portion of the Earth's southernmost continent as well as the characteristics of its sub-glacial morphology. ${ }^{1}$ Beneath the white and pristine Antarctic surface an entire new world was uncovered in greater resolution than ever previously possible, a world made of valleys, mountains, lakes and plateaux in which the ice goes as deep as 4,776 metres. These revelations were realized through airborne radar depth (or radio echo) sounding, in which radio wave pulses are reflected at the ice base. Scientists and historians alike have only just begun to appreciate the importance of radio echo-sounding (RES) in Antarctica. The continent accounts for approximately 90 per cent of all ice on earth - around 70 per cent of its fresh water. An appreciation of the likely response of the ice sheet to future climate changes is clearly urgent. Such appreciation requires numerical modelling of the ice sheet, making RES data vital to any study that sets out to understand variations in sea levels and climate.

* Simone Turchetti, Division of History and Philosophy of Science (HPS), University of Leeds, UK (corresponding author: S.Turchetti@leeds.ac.uk); Katrina Dean, British Library; Simon Naylor, Department of Geography, University of Exeter, UK; Martin Siegert, School of GeoSciences, University of Edinburgh, Scotland.

Research for this paper was generously funded by the Leverhulme Trust, grant number F00144AV. The authors wish to thank the librarians and archivists at the Scott Polar Research Institute, the John Rylands Library of the University of Manchester, the Royal Society of London and the British Antarctic Survey, all in the UK, as well as the National Archives and Records Administration and the Byrd Polar Research Center of the Ohio State University, in the USA. We would also like to thank all those who were willing to be interviewed as part of this project. Lastly we would like to acknowledge the support given by the University of Bristol and by Michael Worboys, director of the Centre for the History of Science, Technology and Medicine (CHSTM), University of Manchester, during the completion of this project.

1 D. Drewry (ed.), Antarctica's Glaciological and Geophysical Folio, Cambridge, 1983. 
Given the recent scientific and political debates on these changes, as well as the current scientific activities in the context of the International Polar Year (2007-8), these data today acquire even greater significance. ${ }^{2}$

Historians can look back at the radio echo-sounding of Antarctica as another important example of twentieth-century 'big science', since this was the largest single surveying project to be run in Antarctica between 1967 and 1979. ${ }^{3}$ Funded by the US National Science Foundation (NSF), the scientific programme was organized by the Scott Polar Research Institute (SPRI) of the University of Cambridge. The US Navy provided a long-range aircraft to travel above nearly nine million square kilometres of ice and from 1974 the Technical University of Denmark designed sophisticated RES devices better to sound the Antarctic. So large international organizations, prominent governmental establishments, leading research centres and the military and industry of powerful nations all contributed to make the discovery of sub-glacial Antarctica possible. In so doing they substantially enlarged the scale of basic glaciological fieldwork.

Yet the early days of RES were far less majestic. Indeed, the technique emerged from the terrible recurrence of aircraft accidents and an equally sorry series of experimental errors. In the 1950s radar altimeters used during flights over the poles worked erratically on plateaux covered with ice. As the ice sheet is almost transparent to radio waves the instruments frequently recorded the bottom surface rather than altitude above the ice. Reading the wrong height, pilots at times descended to land and sometimes crashed as a consequence (Figure 1). While exploring the instruments' defects so as to save precious lives and aircraft, researchers realized the potential of radar altimeters in vertical measurements, giving birth to the new technique of ice sounding.

The fact that accidents account for the origins of RES reminds us of the heuristic value of errors in experimental research and of how errors can bring about scientific and technological change. We certainly know a great deal about how technologies can adapt and be adapted to new environments and tasks, either by purposeful construction of new artefacts or by serendipitously exploiting the hidden properties of existing ones. ${ }^{4}$ The available literature shows examples of adaptation by transfer or remodelling and culminates in the evolutionary approach to technological change illustrated by George Basalla. ${ }^{5}$ However, our treatment of the origins of RES adds a novel element to these

2 See R. Fifield, International Research in the Antarctic, Oxford, 1987, 36-7; G. E. Fogg, A History of Antarctic Science, Cambridge, 1992.

3 We use the term 'big science' with reference to the use of long-range aircraft as a polar research 'laboratory' to cover the entirety of the Antarctic continent. We also refer to the setting up of large teams of administrators, pilots, technicians and scientists to fulfil the research task assigned. This does not necessarily imply that our case study is comparable budgetarily with other well-known examples of big science such as high-energy physics. On big science see P. Galison and B. Hevly (eds.), Big Science: The Growth of LargeScale Research, Stanford, 1992; D. de Solla Price, Little Science, Big Science, New York, 1963.

4 On serendipity see R. K. Merton and E. Barber, The Travels and Adventures of Serendipity: A Study in Sociological Semantics and the Sociology of Science, Princeton, 2004; R. M. Roberts, Serendipity: Accidental Discoveries in Science, New York, 1989. On serendipity in big science see C. Westfall, 'A tale of two more laboratories: readying for Fermilab and Jefferson Laboratory', Historical Studies in the Physical and Biological Sciences (2002), 32, 369-407.

5 On technology transfer see T. P. Hughes, Networks of Power: Electrification in Western Society, 1880-1930, Chicago, 1983, 47-78; G. Basalla, The Evolution of Technology, Cambridge, 1989. 


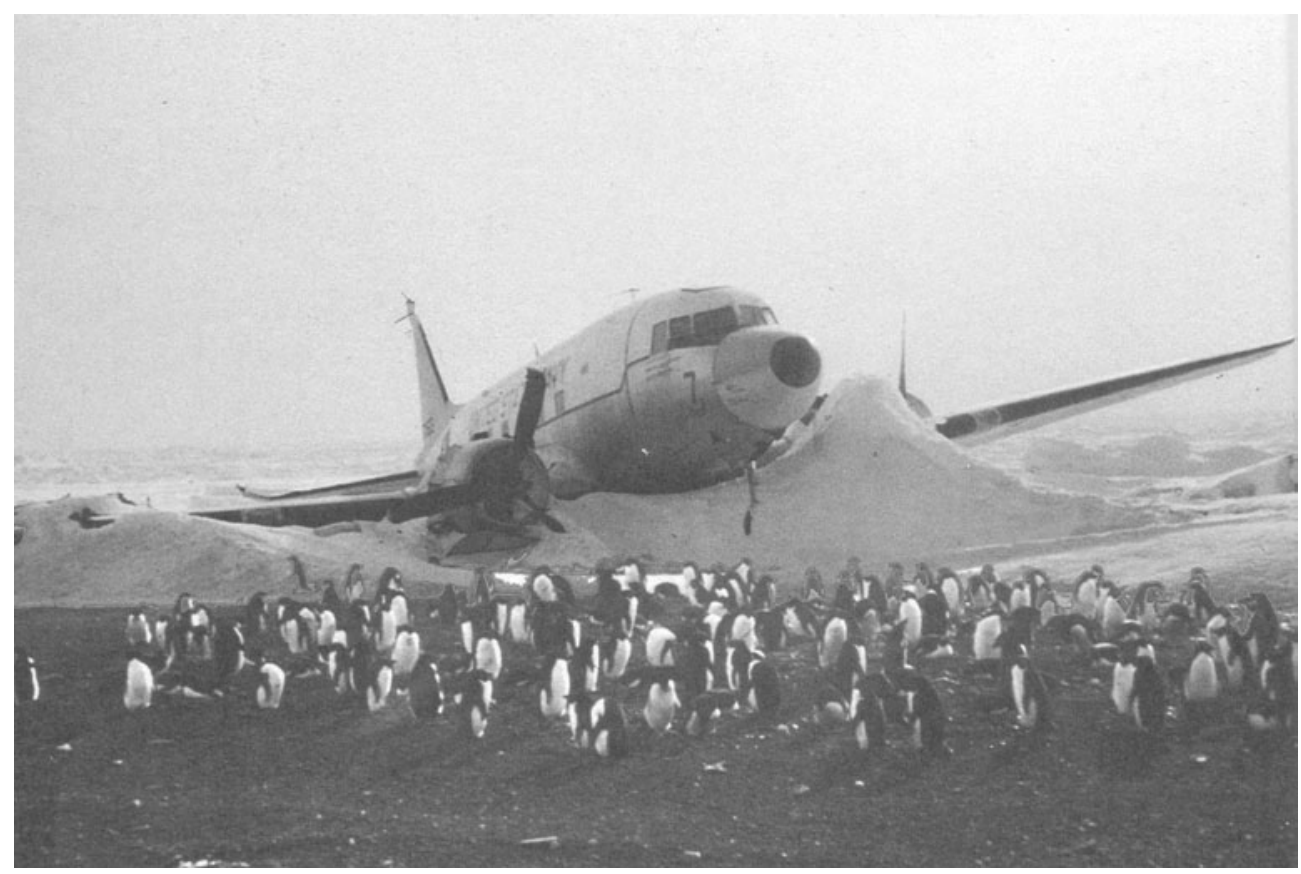

Figure 1. A US Navy R4D crashed at Hallett Station, October 1960. From J. C. Behrendt, The Ninth Circle: A Memoir of Life and Death in Antarctica, 1960-1962, Albuquerque, 2005, p. i. Reproduced with permission of Prof. Behrendt.

arguments by showing that when accidents and errors become the subject of scientific enquiry, they can instigate a broader analysis of the range of applications associated with the experimental apparatus in use and in turn favour its adoption more remotely from its current domain. ${ }^{6}$

Even so, what conditions allowed a few experts tinkering with their flawed experimental devices to enter big science? Here we demonstrate that it was, especially, the opportunity to exploit new and compelling political circumstances typifying Antarctica that helped leading glaciologists in their quest to develop RES. After the International Geophysical Year of 1957-8 (IGY), new structures of governance extended the influence of glaciologists in Antarctic affairs, allowing them to test the potential of new devices. In turn, the Cold War promoted scientific collaboration and competition, creating a climate in which US funding bodies and the military were receptive to the idea of helping glaciologists in their quest for a large-scale survey of Antarctica's sub-glacial morphology using the new sounding technique. Clearly, given the existence of US military activities and interests in polar environments, several scientific

6 For an analysis of the heuristic value of errors in science see J. Schickore, " “Through thousands of errors we reach the truth" - but how? On the epistemic role of error in scientific practice', Studies in the History and Philosophy of Science (2005), 36, 539-56. On the importance of error-making in computing see S. Mols, 'Error-mindedness and the computerisation of crystallography, 1912-1955', Ph.D. dissertation no. 27296, University of Manchester, 2006. 
programmes had already developed by the time of the IGY. ${ }^{7}$ Yet it was because of the interchange between science and international politics in Antarctica following the IGY that glaciology became a central component of US foreign relations, fuelling the patronage of those international scientific endeavours that now acquired diplomatic and strategic significance. The gathering of basic geophysical data and the refining of remote sensing technologies, including RES, thus served geopolitical as well as scientific ends. ${ }^{8}$

Technological breakthroughs were also fundamental to RES's trajectory. The new sounding technique relied on the coordination of innovative technologies for airborne transport and navigation, newly developed imaging technologies and newly designed electronic equipment. In fact RES was only one piece in a network of equally important technological components that were part of a purposely designed NSF 'airborne laboratory' which was aimed at being an innovative remote sensing platform for polar studies. ${ }^{9}$ In the coordination and synchronization of the complex technological system related to RES deployment in the field, serendipity gave way to prediction. Accident was reduced to a minimum by rigorous preparation and clockwork execution.

Our study thus examines the interplay of accidents and opportunities in the history of RES, from its inception to its deployment in Antarctica and from its serendipitous origins to its aftermath as a big-science project typified by political influence, prediction, technological prowess and large investments.

\section{Serendipity part I: the hidden returns of gross errors, 1955-60}

The transparency of ice to certain radio frequencies was first identified in the late 1920s. In 1927 a new method was developed to measure glacier ice thickness by electrodynamic means and in 1933 American explorers gathered indicators of the transparency of ice to high-frequency radio waves at the Antarctic station of Little America on the

\footnotetext{
7 US military patronage of post-war Arctic and Antarctic research had been vital to the development of important branches of the environmental sciences, including glaciology and geophysics; see R. Doel, 'Constituting the postwar earth sciences: the military's influence on the environmental sciences in the USA after 1945', Social Studies of Science (2003), 33, 638-40. For an overview of US patronage of European scientific organizations in the post-war years see J. Krige, American Hegemony and the Postwar Reconstruction of Science in Europe, Cambridge, MA, 2006.

8 In this respect our case parallels those of seismology, oceanography and cartography. See Kai-Henrik Barth, 'The politics of seismology: nuclear testing, arms control and the transformation of a discipline', Social Studies of Science (2003), 33, 743-81; J. D. Hamblin, Oceanographers and the Cold War: The Disciples of Marine Science, Seattle, 2005; J. Cloud and K. C. Clarke, 'Through a shutter darkly: the tangled relationships between civilian, military, and intelligence remote sensing in the early U.S. space program,' in Secrecy and Knowledge Production (ed. J. Reppy), Ithaca, NY, 1999, 36-56; J. Cloud, 'American cartographic transformations during the Cold War', Cartography and Geographic Information Science (2002), 29, 261-82. For a similar case in biology see R. McLeod, 'Strictly for the birds: science, the military and the Smithsonian's Pacific Biological Survey Program, 1963-1970', Journal of the History of Biology (2001), 34, 315-52.

9 On relations between field and laboratory see R. Kohler, Landscapes and Labscapes: Exploring the Lab-Field Border in Biology, Chicago, 2002.
} 
Ross Ice Shelf. ${ }^{10}$ But lack of development in radio technologies and poor funding made it impossible to explore the matter further. Indeed, it was quickly forgotten. It was not until the 1950s that it suddenly re-emerged in the scientific literature for entirely different reasons. Radio engineers realized that radar altimeters did not work efficiently on Antarctic plateaux. Owing to the ice's transparency to radio waves, altimeter readings were sometimes erroneous, jeopardizing the safety of aircraft and their crews.

The radar altimeter was born out of wartime research. The Second World War marked the development of new systems of radio detection and ranging (radar) in the US and in Britain (known as RDF - radio direction finding), which assisted the better manipulation of radio waves for military purposes. Radar systems were used in the context of ground defence networks, but the provision of portable airborne systems was also prioritized because of the new requirements of strategic bombing. ${ }^{11}$

Aside from their influence on military operations, radar technologies also transformed altitude measurement, paving the way for the introduction of new apparatus that would signal the height of an aircraft by transmitting radio pulses to the surface and calculating altitude from the returning echo. Radar altimeters were first conceived in the second half of the 1930s and fully developed in the 1940s. One of the conventional models used by US military aircraft was the SCR $718 .^{12}$ This portable radar apparatus, an improved version of the SCR 618 and SCR 518 models (also named AYA, or high altitude pulse altimeter), was designed as a technological aid in high-altitude bombing, photographic mapping and terrain clearance. Radar altimetry developed in the US thanks to institutions such as the US Army Signals Research Corps based in Fort Monmouth, NJ and saw the involvement of a number of large US electronics firms.

Altimeters of the SCR 718 type were effective and reliable in normal conditions, but functioned erratically on land or sea substantially covered with snow and ice. Some of the first evidence of these problems emerged during Operation Highjump (1946-7), which marked the first US attempt to train and overwinter in Antarctica. Organized by the US Navy in the context of its Antarctic Development Program, the operation was aimed at establishing US bases in Antarctica, thereby consolidating American sovereignty, and at gathering knowledge on Antarctica's morphological, geographical and geological features. ${ }^{13}$

But when Operation Highjump began and when new 'Deep Freeze' missions were organized by the Navy every year from the mid-1950s, airborne logistical support for

10 W. Stern, 'Principles, methods and results of electrodynamic thickness measurement of glacier ice', Zeitschrift für Gletscherkunde (1930), 18, 24. See also S. Evans, 'Correspondence', Polar Record (1963), 11, 795. On Little America's observations see A. Waite and S. J. Schmidt, 'Gross errors in height indication from pulsed radar altimeters operating over thick ice or snow', Proceedings of the Institute of Radio Engineers, IRE, June 1962, 1515-20.

11 New devices such as modulators (klystrons and cavity magnetrons) allowed the production of pulses of high frequency $(\mathrm{HF})$ or very high frequency $(\mathrm{VHF})$ that also augmented the power of radar transmitters and receivers. See R. Buderi, The Invention that Changed the World: The Story of Radar from War to Peace, New York, 1996.

12 The acronym SCR is of unclear origins: a model produced by the US Army Signal Research Corps or just 'Set, Complete, Radio'.

13 On Operation Highjump see L. A. Rose, Assault on Eternity: Richard E. Byrd and the Exploration of Antarctica, 1946-1947, Annapolis, 1980. See also R. Doel, op. cit. (7). 
US explorations proved rather problematic. Pilots using pulsed-radar altimeters reported 'gross errors' in the measurement of altitude and sometimes crashed as a consequence. From 1955 to 1961 US missions in Antarctica experienced nineteen deaths in aircraft accidents, many caused by poor visibility combined with dysfunctional radar altimeter readings. ${ }^{14}$ For example, on Christmas Eve 1959 a US Navy R4D stalled and crashed. The pilot had read forty feet instead of seventy, thereby thinking he was close to landing. In the words of Antarctic explorer John C. Behrendt,

The pilot dropped the required 40 feet and felt a jerk ... He thought that was the snow surface so he cut the power. Because he was still 30 feet in the air, the plane stalled ... One wing hit the snow, recoiled to the other wing, and the whole plane turned violently and skidded forward. Both wings were severed instantly, and when the fuselage finally came to stop, only the pilot had sustained minor injury to his head. ${ }^{15}$

Work on faulty radar altimeters started in earnest in the very same institution that had pioneered its development: the US Army Signals Corps research facility at Fort Monmouth. Those military personnel who had worked in Antarctica in the context of the US explorations instigated new research. In the mid-1950s US Army engineers measured the ice's electromagnetic properties and demonstrated that snow and ice were transparent to frequencies between 1,000 and $10 \mathrm{MHz}$. This made the deployment of radar altimeters problematic because it included the range $(400 \mathrm{MHz})$ used by the SCR 718. ${ }^{16}$

It was mainly thanks to Amory 'Bud' Waite, one of Fort Monmouth's radio engineers, that the problems associated with radar altimetry on territories covered by snow and ice were fully addressed. Waite was an expert in radar altimetry and a veteran of polar missions. He had participated in eighteen polar expeditions, eight in Antarctica and ten in the Arctic. In the 1950s Waite embarked on a five-year study of the transparency of ice to radio waves. The reason for these faults was ascertained by Waite thanks to an analysis of the reasons for radio penetration of ice. It became apparent that, owing to the transparency of ice to radio waves, pulses were not reflected by the ice plane but went through the ice and were reflected by the bottom surface beneath the ice. It was the bottom surface that the aircraft radar actually measured. ${ }^{17}$

Thus Waite sought to achieve a deeper understanding of the phenomenon. He pointed out the absence of surface indication when a plane flew closer than 250 feet to the surface of Antarctica with ice thickness of 120 feet. Sometimes the problem existed when the plane was between 200 and 800 feet. Radar altimeters could be 'fatally dangerous' to low-flying pilots. ${ }^{18}$

14 Only from 1970 did this rate drop significantly. J. C. Behrendt, The Ninth Circle: A Memoir of Life and Death in Antarctica, 1960-1962, Albuquerque, 2005, 8.

15 Behrendt, op. cit. (14), 41. Quote taken from G. A. Doumani, The Frigid Mistress: Life and Exploration in Antarctica, Baltimore, 1999.

16 Waite and Schmidt, op. cit. (10), 1520.

17 Waite and Schmidt, op. cit. (10), 1520. E. K. Gannett, 'Radar Altimeters fooled by polar ice and snow', News Release from IRE, 20 March 1961.

18 Waite and Schmidt, op. cit. (10), 1517. 
But the analysis of the SCR 718's erroneous performance helped Waite uncover its hidden qualities: it could be extremely effective at taking vertical measurements. While alerting US authorities to the dangers of flying in Antarctica, Waite also considered the scientific benefits to be derived from the application of radar altimeters to surveys of Antarctic territories. Between 1957 and 1959 Waite's modified radar altimeter was first deployed to carry out ice measurements in Antarctica, thus showing that a device that was hazardous because of its functioning on ice could also be a useful tool to investigate the bottom surface. ${ }^{19}$ Indeed, it was gross errors in radar altimetry that preceded radioglaciology. And, as we shall now see, it was interference with radar apparatus used in ionospheric studies that accelerated its development.

\section{Serendipity part II: the rewards of interference, 1958-63}

In the late 1950s Antarctica was one of the main sites of observation for the study of ionospheric phenomena such as the aurorae. It was by no means perfect, however. Ionospheric research was at times jeopardized by mysterious interfering signals that made it impossible continuously to record echoes from the ionosphere. After several disappointing experiences, the British physicist Stanley Evans understood that the pulses transmitted by ionosondes bounced on the Antarctic bottom surface, interfering with radio echoes. Evans thus concluded that defective ionosondes could well be transformed into tools for glaciological surveying.

In a similar way to radio engineering, radio-echo studies relied upon the use of equipment produced during the Second World War. After the war, US and UK military radar apparatus was lent to scientific groups for research on the ionosphere and astronomical bodies. For example, in 1949 the model SCR 270 was used by a team at the University of Saskatchewan in Canada to carry out studies on the aurora borealis. ${ }^{20} \mathrm{In}$ Britain, wartime radar designers such as the physicist Bernard Lovell deployed military equipment in the study of meteors and satellites, effectively establishing the discipline of radio astronomy. ${ }^{21}$

Radio-echo studies developed rapidly in Britain and the preparation for the IGY provided a remarkable occasion to unite British research centres in common endeavours. The Royal Society of London, which took responsibility for IGY work in Britain, funded new Antarctic projects. Three British research centres were recognized as IGY data banks: the Balfour Stewart Aurora Laboratory of Edinburgh (for aurorae), the SPRI (for glaciology) and the DSIR Radio Research Establishment (RRE) at Slough (for other ionosphere phenomena). ${ }^{22}$

19 S. Evans, 'Radio technique for the measurement of ice thickness', Polar Record (1963), 11, 406-10.

20 P. A. Forsyth, W. Petrie, F. Vawter and B. W. Currie, 'Radar reflexions from auroras', Nature (1950), $4197,561-2$.

21 See D. Saward, Bernard Lovell: A Biography, London, 1984, especially Chapters 10 and 11; B. Lovell, The Story of Jodrell Bank, London, 1968.

22 Special Committee on publications, 26 November 1957, in 'IGY British National Committee-Minutes and Papers', IGY/4/1, Jodrell Bank Archive, John Rylands Library, University of Manchester (hereafter JBA). 
Lovell's brainchild, the Jodrell Bank Observatory (JBO), was fully involved in the Royal Society's initiative and by the mid-1950s JBO personnel had already achieved an excellent reputation in the development of radio-echo instrumentation. In 1955 Evans, a young and promising physicist at Manchester University, was appointed lecturer in radio astronomy at the JBO and in 1956 dispatched to the Royal Society's base in Antarctica at Halley Bay to study the aurora australis. During his fieldwork Evans used an all-sky camera during the Antarctic night and an ionosonde to detect aurorae during daylight, when they are invisible but still produce radio echoes. Evans's work was successful and duly reported in Britain as a major IGY achievement. ${ }^{23}$

Yet Evans's research had been on the point of being completely unsatisfactory owing to the interference of mysterious radio echoes. ${ }^{24}$ As JBO and RRE devices adopted similar frequencies, Evans and Lovell at first believed that the main cause of interference was their combined operation. The RRE investigator Walter Piggott was thus asked to modify his apparatus. But disturbing signals continued to turn up in Antarctica. Piggott was chiefly concerned with the fact that the ionograms - graphs showing detected echoes in terms of frequency against range - had mysterious 'gaps' between continuously recorded echoes.

Four years later these experimental errors became the subject of Evans's research. By then he had moved to the SPRI and continued to publish his earlier research on aurorae. ${ }^{25}$ Evans had got to know Gordon de Quetteville Robin, the SPRI director, through their mutual participation in the IGY. An Australian physicist who graduated in Melbourne in 1939, Robin had moved to Britain after the war. Working at the University of Birmingham under the guidance of Mark Oliphant, Robin established himself as an expert in glaciological research. After a very brief period at the Australian National University, in 1958 he was appointed director of the SPRI and in the same year he invited Evans to work there with him. ${ }^{26}$

In 1960 Piggott visited Evans at the SPRI. By then the RRE researcher understood that the ionograms showed 'gaps' only at very specific low frequencies. Together with L. W. Barclay, Piggott also demonstrated that some signals were reflected at the interface between the ice shelf and the sea beneath it. From this he inferred that their echoes bounced back into the ionosphere and interfered with the signal produced by the ionosondes. The following year Evans analysed ionograms recently produced at three different stations in the Antarctic and found that they showed gaps in continuously

23 Evans's achievements were reported in the British magazine Discovery, as he managed to produce remarkable pictures of the aurora australis. A. Croome, 'The IGY month by month', Discovery, May 1957, 210 .

24 Evans cabled Lovell that it was vital to the success of their programme that the interference problem be solved. Stanley Evans to Bernard Lovell, 25 June 1956, cable R.S.86, in 'IGY Minutes and Reports, Antarctic Subcomittee', IGY 3/1, JBA.

25 S. Evans and G. M. Thomas, 'The southern auroral zone in Geomagnetic Longitude Sector 20E', Journal of Geophysical Research (1959), 64, 1381-8; S. Evans, 'Horizontal movements of visual auroral features', Journal of Atmospheric and Terrestrial Physics (1959), 16, 190-2; idem, 'Systematic movements of aurorae at Halley Bay', Proceedings of the Royal Society A (1960), 256, 234-40.

26 D. Drewry, 'Gordon de Quetteville Robin: A Remembrance', Polar Record (2005), 41, 177-81. 


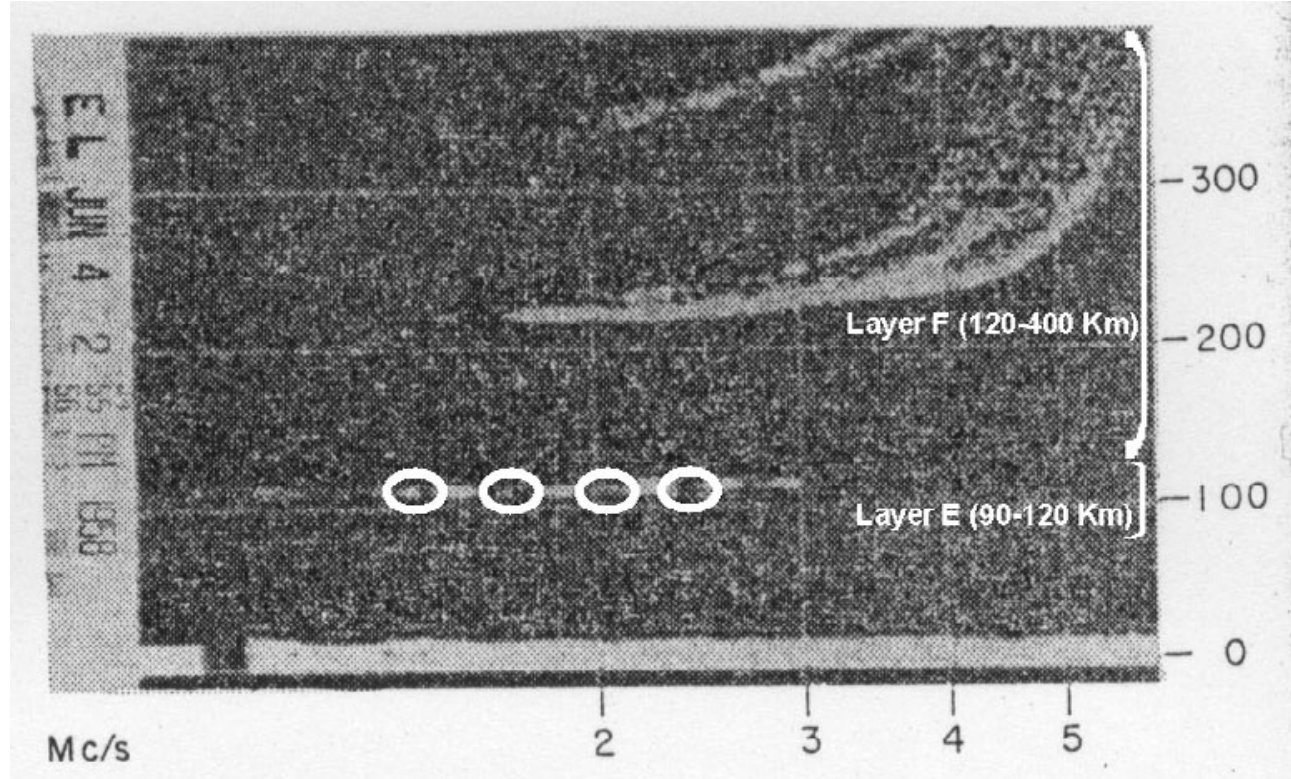

Figure 2. Sample ionogram from Ellsworth with layers and 'mysterious gaps' highlighted. From S. Evans, 'Polar ionospheric spread echoes and the radio frequency properties of ice shelves', Journal of Geophysical Research (1961), 66, 4137-41.

recorded echoes from the layers $\mathrm{E}$ and $\mathrm{F}$ of the ionosphere at certain fixed low-power frequencies ( 1 and $5 \mathrm{MHz}$ ). This confirmed Piggott's findings (Figure 2). ${ }^{27}$

If Waite had initially been concerned with saving pilots' lives, Evans was, at the outset, primarily concerned with ionospheric research. He claimed that studying the interaction of radio waves with ice had the purpose of alerting 'ionospheric workers' to the fact that they 'should bear the presence [of echoes from the bottom surface] in mind when analyzing results from polar stations'. That said, Evans did realize that interfering radio waves may become valuable 'for exploring the bottom topography'. ${ }^{28}$ His analysis of the Antarctic ionograms led him to infer that a radio-echo apparatus working at 30 to $35 \mathrm{MHz}$ had potential for ice-sounding. Robin, who had encouraged Evans's investigation, now suggested designing new ice-sounding apparatus at the SPRI. Funding for development of the instrument was made available through the Royal Society. ${ }^{29}$

27 W. R. Piggott and L. W. Barclay, 'The reflection of radio waves from an iceshelf', Journal of Atmospheric and Terrestrial Research (1961), 20, 298-9. 'This was attributed to the effect of interference between the waves radiated directly upwards from the aerials to that which is radiated downwards through the ice and reflected from the bottom.' Evans, op. cit. (19), 407.

28 S. Evans, 'Polar ionospheric spread echoes and the radio frequency properties of ice shelves', Journal of Geophysical Research (1961), 66, 4137-41, 4141.

29 Evans, op. cit. (28), 4138. See also M. Mulkay, 'Conceptual displacement and migration in science: a prefatory paper', Science Studies (1974), 4, 205-34, 218. Evans was awarded a grant from the Paul Instrument Fund (PIF, established under the will of R. W. Paul, inventor of the 'unipivot galvanometer') and received $£ 2,736$ in May 1962, £1,555 in October 1962 and $£ 1,000$ in September 1973 for the development of an 
By 1963 the new SPRI depth-sounder Mark I was completed and tested at Halley Bay. As in the case of the modified SCR 718, it was aimed at probing the ice. The reasons that led its creator to consider applying radar devices to glaciology were likewise unexpected, the result of serendipitous discoveries taking place (as Evans noticed) 'in two quite separate fields of study' that had virtually nothing to do with glaciology. ${ }^{30}$ Even so, the accidental nature of these discoveries could be fully appreciated only because the study of experimental errors and accidents allowed envisaging different uses of existing apparatus and its readaptation to glaciological research.

\section{In the glaciologists' hands: the development of RES, 1961-6}

Whilst Evans and Waite were busy exploiting the defects of their devices, major political changes were occurring that altered significantly Antarctica's geopolitical circumstances. The success of scientific projects in Antarctica during the IGY paved the way for the establishment of the Scientific Committee on Antarctic Research (SCAR). SCAR was established in October 1958 as a 'Special' (later 'Scientific') Committee of the International Council of Scientific Unions (ICSU). SCAR was an international organization devoted solely to the promotion, planning and coordination of research in the Antarctic. Twelve countries (the USA, the UK, France, Australia, New Zealand, the USSR, Argentina, Chile, Belgium, Japan, Norway and South Africa) made contributions to its initial budget. ${ }^{31}$ In 1959 the countries operating SCAR signed the Antarctic Treaty (AT), which came into force on 23 June 1961. The treaty was an agreement to set Antarctica aside for peaceful purposes and particularly for science, while all claims to portions of Antarctic territory were forestalled. ${ }^{32}$ This helped defuse tensions between signatory members, especially with regard to those nations whose claims to Antarctic territory overlapped (notably Argentina, Chile and Britain). It also helped each superpower (the USSR were newcomers to Antarctica) to prevent the other making exclusive claims on portions of Antarctic territory. Moreover, the treaty established the principle at the height of the Cold War that in Antarctica there would be no military or nuclear installations on the continent and that each country could perform inspections on another country's bases. Yet military forces continued to play a major role in Antarctic affairs and to have a significant presence on the continent, especially as a

echo-sounder for ice-thickness measurements. 'PIF Grants', MS 840/1, Royal Society Archives, London. Michael ('Mike') E. R. Walford assisted Evans in the construction of the instrument.

30 Evans, op. cit. (19), 406.

31 Within SCAR, eight working groups were also set up: Biology, Geodesy and Cartography, Geology, Glaciology, Human Biology and Medicine, Logistics, Solid Earth Geophysics, Upper Atmosphere Physics. See Fifield, op. cit. (2), 5 .

32 The twelve signatory members, 'Recognizing that it is in the interest of all mankind that Antarctica shall continue for ever to be used exclusively for peaceful purposes ... and Acknowledging the substantial contributions to scientific knowledge resulting from international cooperation in scientific investigation ... Agreed that Antarctica shall be used for peaceful purposes only ... (Article 1) and that Freedom of scientific investigation in Antarctica and cooperation toward that end, as applied during the International Geophysical Year, shall continue, subject to the provisions of the present Treaty (Article 2).' The Antarctic Treaty, 1959. (The whole treaty is available at http://www.antarctica.ac.uk/About_Antarctica/ Treaty/treaty.html.) 
logistical aid to international collaboration between research groups. As Fae Korsmo has argued, after the IGY 'the interests of scientists and national security coexisted in alignment and mutual support'. ${ }^{33}$ Moreover, full AT membership was only granted to those states able to invest substantially in scientific research, which usually meant the ability to establish and maintain a scientific research station in Antarctica. The SCAR (now a 'Scientific' committee) was given the function of the AT's chief science advisory body in Antarctica's novel system of governance. SCAR became a platform for the coordination of scientific research and so acquired new diplomatic significance. ${ }^{34}$ This arrangement effectively allowed scientists with common research interests to organize new investigations, which in the light of the treaty gained a geopolitical emphasis. Glaciologists who had spent time in the Antarctic as explorers had a prominent role in the organization of SCAR. Robin achieved positions of responsibility within the organization, as UK delegate from 1958 and as SCAR executive secretary from 1959. At the fourth SCAR annual meeting, held in Cambridge in 1960, the British delegation was represented by Robin and assisted by Evans as adviser. In the same period the US SCAR delegation was also composed of glaciologists who had now become science administrators. Amongst others was Albert 'Bert' Paddock Crary (known to Robin because of their mutual research activities in the poles), one of the US advisers during these meetings and the secretary of the SCAR working group on logistics. ${ }^{35}$ Crary was the first person to have reached both poles and played a leading role in the organization of the IGY in Antarctica, managing US traverses across the Ross Ice Shelf. In 1961 he was appointed chief scientist of the US Antarctic research programme and codirector of the newly established NSF Office of Antarctic Programs (OAP), which also greatly extended his influence.

The positions that Crary and Robin came to occupy allowed them to promote new means of glaciological exploration. Robin in particular had pioneered techniques of icesounding based on seismic reflection and gravity measurements during the Norwegian-British-Swedish Antarctic Expedition of 1949-52. Seismic reflection involved exploding charges of dynamite in ice holes and, with the help of geophones (miniature seismographs), gathering data on the ice depth. The idea of mapping Antarctica's sub-glacial morphology had motivated Crary's research since its inception, also leading to a plan to exploit traverses to prepare a 'plastic relief map' of the continent. ${ }^{36}$ Both Robin and Crary were aware, however, that traditional techniques of sounding were inadequate for far-reaching projects such as the detailed mapping of

33 F. Korsmo, 'Science in the Cold War: the legacy of the IGY', NSF Special Scientific Report 98-07, 7 April 1998. See also F. Korsmo and M. P. Sfraga, 'From interwar to Cold War: selling field science in the United States, 1920s through 1950s', Earth Sciences History (2003), 22, 55-78.

34 A. Elzinga, 'The interplay of research and politics: the case of Antarctica', in Society and the Environment: A Swedish Research Perspective (ed. U. Sverdin and B. H. Anisansson), Dordrecht, 1992, 257-83. See also K. Dodds, Geopolitics in Antarctica: Views from the Southern Oceanic Rim, New York, 1997.

35 'SCAR Bulletin. 4th meeting, Cambridge, 29.8/2.9.1960', Polar Record (1960), 10, 416.

36 H. K. Bourne (UK scientific observer in Antarctica), 'Some Notes on Polar Research', undated (but early 1960s) in AD3/1/AS/131/1 (2) Part 2, BAS Archives, Cambridge (hereafter BAS). On the origins of seismic reflection see C. C. Bates, T. F. Gaskell and R. B. Rice, Geophysics in the Affairs of Man, Oxford, 1982. 
sub-glacial Antarctica. A major drawback was that their deployment in large territories was costly and of limited accuracy. Moreover, traditional probing tools could not provide continuous profiling.

RES gave Crary and Robin the opportunity to determine whether the limits of traditional techniques could be overcome. Crary was aware of Waite's research and in 1962 proposed that the radio engineer attend the SCAR annual meeting. The initiative led to the organization of an international experiment to 'quickly evaluate each [glaciological surveying] system regarding its accuracy, speed and cost per mile of survey'. ${ }^{37}$ It was for this reason that it was suggested to Robin as SCAR executive secretary that the Thule military base in Greenland be used as a site to test the most advanced systems of glaciological sounding. Thanks to an intervention by Waite the US Army welcomed the proposal of an international experiment promoted as an exercise in international collaboration. ${ }^{38}$ In that respect the experiment was consistent with a vision embodied in post-IGY US science policy. As shown by Ronald Doel and Allan Needell, US science administrators such as Lloyd Berkner believed there was little contradiction between international exchange of scientific data and close collaboration with US military branches. In fact the collaboration carried added propaganda value by showing the triumph of science over politics. And it could, more pragmatically, help US researchers gather a deeper understanding of ways to develop frontier research. ${ }^{39}$ Of course, the new policy was always balanced between scientific gains and security risks. It is notable, for instance, that no Russian was invited to attend the 'international experiment'.

The tests were carried out in April 1963 and compared seismic, gravity, radio echosounding and electrical resistance methods. Waite's modified SCR 718 (at 110, 220 and $440 \mathrm{MHz}$ ) and Evans's SPRI Mark I (at 30 and $35 \mathrm{MHz}$ ) were both tested. Most seismic and gravity measurements were conducted with equipment provided by Charles Bentley, of the Geophysical and Polar Research Centre (GPRC), University of Wisconsin, in the US. Bentley's expertise in the field was by then well known, as he had also participated in the seismic traverses of the IGY and was the US representative of the SCAR working group on glaciology.

The 'international experiment' produced mixed results but showed a communal interest in further exploration of the potential of RES. ${ }^{40}$ During the following Antarctic

37 A. Waite, 'The International Cooperative Experiment on Glacial Sounding, sponsored by USAEL and USACRREL, Greenland 1963 and 1964', paper presented at the Glacier Mapping Symposium, Canadian National Research Council, Ottawa, 15 September 1965.

38 The headquarters of the US Army Electronics Research and Development Laboratory were based in Thule, a US Air Force base and a vital and heavily militarized centre in North America's first line of defence in the Arctic. C. Swithinbank, Forty Years on Ice: A Lifetime of Exploration and Research in the Polar Regions, Sussex, 1998, 79.

39 R. Doel and A. A. Needell, 'Science, scientists and the CIA: balancing international ideals, national needs and professional opportunities', in Eternal Vigilance? 50 Years of the CIA (ed. R. Jeffreys-Jones and C. Andrews), London, 1997, 59-81.

40 Waite claimed that the radar altimeters and radio-echo equipment 'worked successfully'. Evans, however, claimed that the apparatus had worked efficiently but was not powerful enough. S. Evans, 'International cooperative field experiment in glacier sounding', Polar Record (1963), 11, 725-6. According to an anonymous reviewer, 'Waite failed to obtain good results with his high-frequency altimeter, he obtained virtually 
summer, Evans's assistant, Mike Walford, took the SPRI Mark I to Halley Bay to develop the first test of its accuracy in glacier measurements. ${ }^{41}$ In the meantime Evans decided to work on an improved version of the echo-sounder equipped with an imaging device that continuously recorded on film the pulse traces as pictured on an oscilloscope, a device used to trace electronic signals that are fed into cathode ray tubes. The SPRI Mark II was tested in Thule, Greenland, in June and July 1964, when a new phase of the international experiment was set up. This time the echo-sounders proved more efficient and successfully recorded depths of 1,500 meters. Even Evans became convinced after these trials that RES was a viable technology for the task at hand. ${ }^{42}$

Various types of echo-sounder were all deployed in Antarctica experimentally from the mid-1960s. Waite's apparatus was loaned to the GPRC's personnel for use in the context of NSF-funded research activities taking place during US traverses. In 1966, following the Greenland experiments, the SPRI Mark II was tested in the air. It was first used at Ellesmere Island, Canada, in a joint mission organized by SPRI with the Canadian Defence Research Board. The team flew an Otter aircraft over the island and recorded very satisfactory RES data. Afterwards the apparatus was loaned to Charles Swithinbank of the British Antarctic Survey (BAS), who brought it to Halley Bay and, together with David Petrie, flew it on the Swiss-built Porter 'Pilatus'. ${ }^{43}$ If several groups could now deploy RES in polar projects this was by and large because of the international experiment, itself an offspring of the SCAR and AT initiatives.

Despite accidents, ${ }^{44}$ by 1966 RES had reached a stage in its development that allowed consideration of its deployment in large-scale research projects aimed at exploring Antarctica's sub-glacial morphology. Its technical features had proved it more efficient than traditional techniques of sounding on land and fostered its experimental use in airborne surveying. Moreover, the new geopolitical circumstances outlined by the AT had given Crary, the OAP chief scientist, the opportunity to reconsider his attempt to map sub-glacial Antarctica. Under his guidance the OAP was now planning to establish an 'airborne laboratory', including a number of remote sensing and reconnaissance devices (echo-sounders, radar altimeters, aerial photographic instruments, infrared sensors and magnetometers) for the purpose of providing basic

continuous echoes'. Anon., 'RES', Ice (1962), 16, 10-12. Finally, Bentley claimed that the ' $30 \mathrm{MHz}$ system did better than Bud's [Waite] $440 \mathrm{MHz}$ system, because I remember there was a frequency factor ... 440 was, it was just too high frequency ... Stan's system failed before we got very deep, but still it was, it proved that the system had worked, and then it was just a matter of continuing development.' Interview with Professor Emeritus C. Bentley at the University of Wisconsin-Madison, USA, 6 October 2005.

41 M. E. R. Walford, 'RES through an ice shelf', Nature (1964), 204, 317-19.

42 Evans wrote, 'these operations represented the biggest leap forward in technique and analysis so far'. They especially helped to consider the greater accuracy provided by RES systems with respect to seismic sounding. S. Evans, 'Progress Report on RES', Polar Record (1967), 13, 413-20, 414. It is worth noting that the use of visual feedback made RES similar to marine echo-sounding, even though the latter is based on acoustic - rather than electromagnetic - means of remote sensing.

43 Swithinbank, op. cit. (38), 36.

44 In October 1965 one of Evans's assistants, J. T. Bailey, died in a crevasse whilst surveying a large unknown sector from Halley Bay to the Weddell Sea. He and two attendants, D. Wild and J. Wilson, lost their lives 250 miles from the base. His mission logbook is at the SPRI. See 'Bailey's logbooks, 1965', T. H. Manning Archive, SPRI, University of Cambridge (hereafter THMA). 
geological and glaciological data on the whole continent. ${ }^{45}$ Whilst NSF funding for traditional traverse work began to be constrained, that available for airborne RES was increased. ${ }^{46}$

These developments also followed an analysis of what the Soviet Union was doing in this field, as forms of scientific competition (aside from collaboration) set in. By the mid-1960s the USSR had invested only half of what the US had spent in Antarctica. Nonetheless, Soviet traverses had allowed Russian scientists to gain a good understanding of its glaciological structure, as well as to develop new technologies. From 1964 they had developed RES instrumentation using a frequency of $211 \mathrm{MHz}$ at the Arctic and Antarctic Scientific Research Institute in Leningrad. Although the instrument was successfully deployed to map Eastern Antarctica during the Ninth Soviet Antarctic Expedition (1965-6), at the beginning it was not airborne and it did not make use of continuous film recording. The advantages and limitations of Soviet RES technologies were well known and they certainly instigated a scientific race to deploy a new surveying method based on airborne radio echoes. ${ }^{47}$

Despite the success of the international experiment the NSF did not immediately look at the SPRI as a viable partner for RES-surveying Antarctica. The NSF chief candidate was Waite's organization, the US Army Electronic Laboratories (USAEL, ex-US SCR). A 'preliminary forecast' on US Antarctic research activities for the 1966-7 season indicated that the USAEL was going to work under a 'programme of ice thickness measurements' as part of the airborne-laboratory project. The NSF allocated funding and the US Navy squadron VX-6 made one of its aircraft available. ${ }^{48}$ Aside from advantaging US glaciological groups, there may have been technical reasons that convinced the NSF administrators to favour a partnership with the USAEL. The film-recording technique used by Evans appeared to US experts too cumbersome, not to mention impractical. Bentley's assistant George Jiracek had been unimpressed by Evans's equipment, on which he reported negatively after the 1964 international experiment. The GPRC and USAEL staff preferred techniques to reduce data to numbers, later computerized. ${ }^{49}$ Waite's equipment never developed a visual monitoring

45 Detailed description of the plan is in Appendix I - Airborne Laboratory, 44-6 of 'Plans for U.S. Science Activities in Antarctica, 1968-1972 (Five Year projection)', 1 June 1968, in 'Budget', Box 1, NSF 307/32, US National Archives and Record Administration, Washington, DC (hereafter NARA).

46 In 1965 the OAP codirector, T. O. Jones, wrote to Crary about Bentley's programme, stating that 'I am assuming that we can avoid a traverse in the 1966-67 summer. Bentley has talked about a small Pole to Ellsworth Mountain traverse, but because of the possibilities of an air-borne radio-sounder, I would rather not operate the traverse at least for a number of years'. T. O. Jones to A. P. Crary, 30 August 1965, in 'Budget', Box 1, NSF 307/32, NARA.

47 As the note 'Soviet Antartic maps', Polar Records (1961), 10, 528, shows, mapping activities of Soviet parties had been monitored since the late 1950s. Evans had been especially interested in Russian advancement in radio-glaciology and visited Leningrad in 1966. Evans, op. cit. (19), 413-20; idem, 'Fale radiowe w badaniach glacjologicznych', Prezglad. Geofizyczny (1967), 12, 383-400. On Soviet maps see V. G. Bakaev, Atlas of Antarctica, Moscow, 1966.

48 A sum of $\$ 30,000$ had been already allocated for this plan. T. O. Jones to A. P. Crary, 30 August 1965, and 'Preliminary forecast of 1966-7 U.S. Antarctic Research Program Activities (Prepared for the Naval Support Force, Antarctica Conference)', 9 August 1965, in 'Budget', Box 1, NSF 307/32, NARA.

49 Jiracek reported that 'Evans puts a lot of emphasis on the need for a video amplifier prior to the intensity modulation. I'm sure his emphasis is well founded but I'm not clear as to what his reasons are, therefore not 
technology. Jiracek's criticism shows the existence of different experimental cultures that defined different avenues in the development of RES. ${ }^{\mathbf{5 0}}$ Evans clearly saw imaging as an essential addition to RES that could offer a better understanding of Antarctica's glaciological features, in contrast with Jiracek and Waite, who believed that a quantitative understanding would suffice for the task. ${ }^{\mathbf{1}}$

At some point during 1966 Crary sought to align the RES project with Robin's institution rather than with USAEL. ${ }^{52}$ The reasons for reversing decisions taken the previous year remain unknown, but presumably derived from an evaluation of scientific, political and administrative gains associated with establishing an NSF-SPRI partnership. Crary had always sympathetically viewed Robin's effort to contribute to the development of radio-glaciology at the SPRI. For example, as trustee of the Ford Foundation he had been instrumental in helping the SPRI director get funding for the construction of a new building including an electrical laboratory. In 1965 the foundation awarded \$280,000 for the project. ${ }^{53}$ The 1966 airborne RES tests may have convinced Crary that Evans's device had greater potential than Waite's. The muchcriticized photographic technique used in Evans's device allowed Swithinbank to visualize the sub-glacial morphology of the Antarctic Peninsula and offered a wealth of data on bedrock structure and ice layering. ${ }^{54}$ Moreover, the collaboration with the SPRI would align the OAP's activities with post-IGY science policy in the US, fostering international collaboration alongside national scientific endeavours.

The proposed NSF-SPRI collaboration did not entail a provision of funding for the SPRI personnel, in contrast with the USAEL's proposal, but would only lead to the provision of free hours of flight and transport to SPRI personnel to carry out surveys in Antarctica in coordination with the US Navy's VX-6. This is not to say that Crary was necessarily worried about money as such. Rather, the partnership allowed him to make better and more rational use of NSF resources. In turn, Crary's plans strengthened those of Robin to gather British funding for the deployment of RES. The opportunity to collaborate with the NSF helped Robin to gather additional resources for the initiative

convinced of its importance ... Also I feel that recording is tedious, of questionable accuracy, and very time consuming'. G. R. Jiracek, 'RF equipment considerations', 17 August 1964, in 'Experiments in radio sounding of Polar ice thickness', Paper 86-5355, copy in C. Bentley's Papers at the Byrd Polar Research Center, The Ohio State University Archives.

50 For a technical analysis of the differences between the RES systems see L. A. Plewes and B. Hubbard, 'A review of the use of radio-echo sounding in glaciology', Progress in Physical Geography (2001), 25, 2, 203-36, 209.

51 It seems to us the real issue was not one of technological superiority, but rather one of traditions or 'material cultures' in instrument- and experiment-making. One may even draw on P. Galison's notions of 'image' (Evans) and 'logic' (Waite, Jiracek) to explain it. P. Galison, Image and Logic: A Material Culture of Microphysics, Chicago, 1997.

52 A. Crary to G. Robin, 12 January 1967, in 'Glaciology ice sounding by radio techniques (Dr. Evans), 1962-1972', AD3/1/AS/139 (3), BAS. Drewry, op. cit. (26), 179, seems to suggest that this followed Robin's initiative.

53 See 'Foreword', Polar Record (1965), 12, 681. The operating budget of the foundation for supporting research worldwide was in the range of twenty million dollars. On the funding activities of the Ford Foundation see Krige, op. cit. (7), 172-3.

54 On returning to Britain in February 1967 Swithinbank had shown Crary the preliminary results of his Antarctica RES flights, which had excited the latter. Swithinbank, op. cit. (38), 40. 
through the British Natural Environmental Research Council (NERC), which in 1967 awarded the SPRI $£ 65,000$ over the following three years. ${ }^{55}$

On the whole, the collaboration between the NSF and the SPRI materialized Crary's and Robin's early prospects of mapping the glaciological structures of the entire continent. Plans would be put forward at the NSF to make sure that the whole of Antarctica could be mapped (Figure 3). Big science in radio-glaciology was about to begin.

\section{Synchronicity: the Antarctic missions, 1967-79}

From 1967 to 1979 much of the Antarctic bottom topography was revealed through the deployment of RES in the context of the collaborative SPRI-NSF project. ${ }^{56}$ Later, another organization, the Elektromagnetisk Institut of the Technical University of Denmark (TUD), became involved. Robin, with Evans, led most of the missions, although from the 1974-5 season leadership passed to the SPRI senior scientist David Drewry. Educated at the University of Cambridge, Drewry had participated in the development of RES since the Greenland experiment. His experience and knowledge of RES allowed him to lead the missions to completion with the publication of the Antarctic glaciological maps mentioned at the start of this paper.

Over the course of twelve years there were many changes in the scope and functioning of the project. From 1970 Crary was no longer the OAP director. In the same year the NSF bureau became the Office of Polar Programmes (OPP), in an attempt to place equal emphasis on fundamental research in the Arctic as well as the Antarctic. The restructuring process also affected the NSF-SPRI project, which had to conform to the new OPP agenda. Its new director, Philip M. Smith, indicated the need for the OPP to focus on big-science projects with an international character, thereby moving beyond the traditional institutional setting defined by SCAR. ${ }^{57}$ In May 1969 the US, the USSR, Australia and France joined in a new International Antarctic Glaciological Programme (IAGP) aimed at exploring East Antarctica. The RES project became an integral part of IAGP and concentrated on sounding that vast territory during the second and, especially, the third missions. The setting up of IAGP and its use in connection with the NSF-SPRI project showed that the institutional landscape of international collaboration in radio-glaciology had changed over the years, adapting to new interests and agendas. ${ }^{58}$

But these changes did not significantly affect the research modus operandi during the missions. The deployment of RES relied upon the capacity of glaciologists to interact with experts from other fields and use other technologies as aids during missions. Flight planning relied upon radio-transmitted satellite pictures of meteorological systems,

55 NERC continued funding the SPRI in relation to the joint initiative for the following thirteen years.

56 The first mission in 1967-8 also included the BAS.

57 Smith to Robin, 25 March 1970, in 'UK 1970', Box 31, NSF 307/64, NARA.

58 Smith argued that aside from political concerns, there were also financial concerns for the new strategy of funding, as the new US science policy tried to cut down on the number of organizations requiring financial assistance to keep them running. Smith to Robin, 7 May 1970, in 'UK 1970', Box 31, NSF 307/64, NARA. 


\section{Airborne Laboratory Flight Lines}

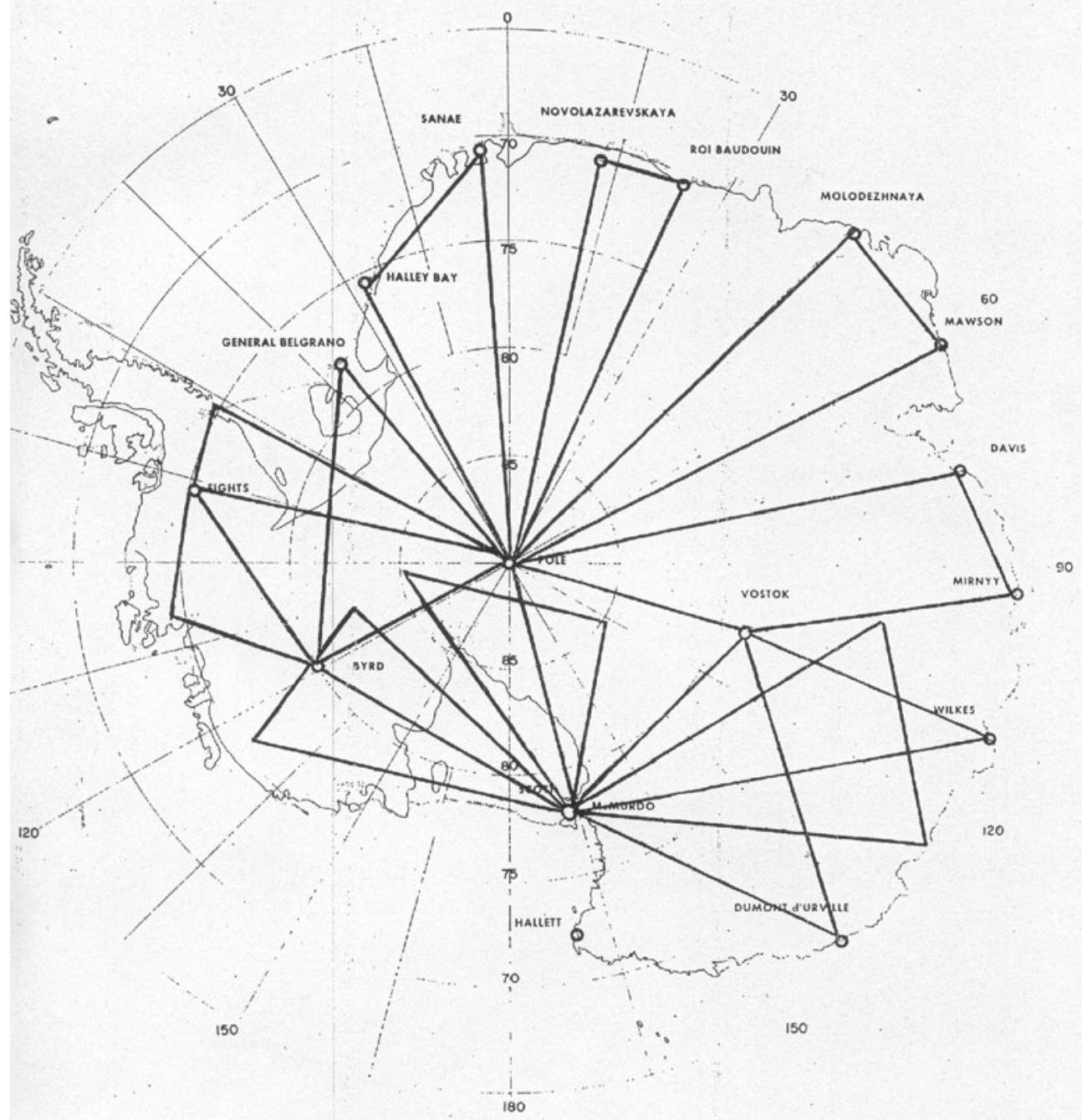

Figure 3. Mapping Antarctica. The flight lines originally planned at the NSF. From 'NSF Plans for US science activities in Antarctica, 1968-1972', Box 32, 307, NARA, Washington, DC.

flight operations depended on the aircraft's technology, and the performance of radar sounding could be checked only through imaging facilities used to picture pulses (Figure 4). Rigorous planning, synchronization and coordination were thus essential. Errors and accidents, which had been so valuable in the origins of RES, were now reduced and, as much as was possible, eliminated. 


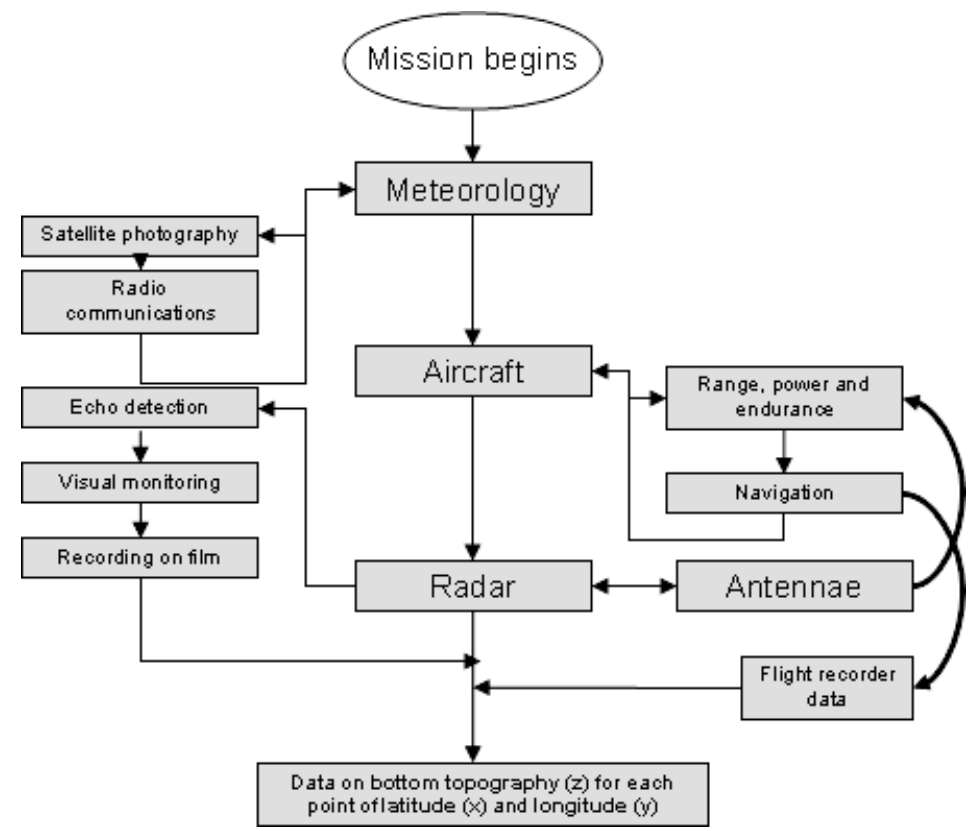

Figure 4. RES and the 'airborne laboratory', 1967-79.

Before each mission the SPRI and the US Navy would debate what portion of the Antarctic continent they would cover, with negotiations often lasting several months. SPRI crews would then be flown from Washington, DC to Christchurch airport in New Zealand and from there to the US Antarctic base of McMurdo Sound. Missions changed considerably from one season to another and became far more complex than was initially foreseen. ${ }^{59}$ Even before flying across Antarctica the RES personnel relied on a number of technologies to analyse weather conditions. Plans could be changed at any time if meteorological observations indicated the impossibility of flying over certain areas due to poor weather. ${ }^{60}$ Data were gathered from satellite photography using the NIMBUS and ESSA satellite systems. The pictures were analysed daily, demonstrating the importance of efficient radio communications as they allowed the transference of photographic data to McMurdo.

59 In interview Drewry agreed that it was a sort of 'military campaign': 'The optimal situation was to have two flight crews in operation in order to have maximum flying time. When one crew came in another would be ready to go out. They would have the program planned two or three flights ahead. But they couldn't go beyond that due to changing conditions and requirements. They would try to get the flight crews to compete with each other in order to cover the most territory. They explained to the Navy personnel what they were trying to do and tried to recruit them to the cause of polar exploration, get them involved so they would get the best outcome for the flight campaign. All sorts of information had to be coordinated in the planning room.' Interview with Professor David Drewry at the University of Hull, UK, 6 April 2004.

60 Although the RES system would work efficiently regardless of these conditions, the navigation apparatus of the aircraft was more likely to be affected. S. Evans, D. Drewry and G. Robin, 'RES in Antarctica, 1971-1972', Polar Record (1972), 16, 207-12. 
RES apparatus epitomized the integration of radio engineering and imaging technologies. Echo detection was obtained through sweeping the frequency band as well as signal attenuation and amplification. The possibility of changing the frequency or attenuating the signal came from the operator, who could monitor radar performance thanks to an oscilloscope. Meanwhile, another oscilloscope attached to a camera was used to record on film the electronic image of probed areas. The performance of radar, oscilloscopes and film cameras was to be coordinated to ensure that the radar worked effectively and that it produced valuable records of the bottom topography. ${ }^{61}$

The need for greater integration marked the transition from the first airborne RES apparatus, the SPRI Mark II, used during the first mission, to the second, the Mark IV. The new apparatus was designed to allow 'automatic annotation of records with the received gain information, also using plug-in modules for rapid servicing in field operation' ${ }^{62}$ It had a new panel allowing immediate control over sweeping operations and camera speed. The SPRI Mark IV was replaced from 1974-5 by a new radar apparatus designed by the TUD, which worked at $60 \mathrm{MHz}$ as well as $300 \mathrm{MHz}$. The Danish system used a new design that allowed operation at higher frequencies and ensured a greater definition of the bottom layers as well as icesheet structure. Its introduction in the design of the new RES system was due to the technical expertise of the Danish radio engineer Peter Gudmansen, of the TUD's Elektromagnetisk Institut.

The beginning of the collaboration with the Danish party, which from the third mission was made responsible for antenna design and from the fourth for RES apparatus, was instigated by the NSF because of several factors. Gudmansen had been responsible for the organization of the first International Meeting on RadioGlaciology at Lyngby in 1970. This had proved an important occasion to share ideas with key players in the development of different radio sounding systems in use. ${ }^{63}$ In contrast with Evans, Gudmansen was convinced that a sounder using pulse amplification granted greater success in profiling ice sheets, and in 1973 with NSF financial support he had tested a new system of this kind in Greenland. While planning the fourth mission the NSF administrators emphasized that sounding work should

61 This coordination was so good that it has preserved the usability of the data to the present. The fact that so much data was recorded in a robust format that withstood the subsequent digital revolution in scientific technologies means that it can still be used for glaciological purposes (even though the navigational errors are far greater than would now occur). Furthermore, with modern digital processing techniques, the analogue data can be processed and scrutinized as if they were new data. Thus the data have acquired a usefulness that was almost certainly not originally envisaged.

62 S. Evans and B. M. E. Smith, 'A radio echo equipment for depth sounding in polar ice sheets', Journal of Physics E: Scientific Instruments (1969), 2, 131-6. The Mark III model was never used during the SPRI-NSF missions because it was conceived for small-scale work, possibly of commercial type, on temperate glaciers.

63 See, amongst others, V. V. Bogorodskij, G. V. Trepov and B. A. Federov, On measuring dielectric properties of glaciers in the field in Proceedings of the International Meeting on Radioglaciology (ed. P. Gudmansen), Technical University of Denmark, Lyngby (Denmark), May 1970, 20-31; P. Gudmansen, 'Notes on radar sounding of the Greenland peninsula', in ibid., 124-33; and S. Evans, 'Review of the radio echo system performance in Gudmansen, P. E.', in ibid., 100-2. For a technical analysis of the differences between the various RES systems see Plewes and Hubbard, op. cit. (50), 210-11. 
concentrate on West Antarctica to assist drilling plans in the proximity of the US base Siple. ${ }^{64}$ Yet the SPRI team was against this solution: because of warm, thick ice the area was difficult to sound. It was then that NSF administrators suggested using Gudmansen's apparatus because it had proved very successful on the Greenland ice sheet, which presented similar problems. ${ }^{65}$ The SPRI team was initially resistant to this solution but the TUD's radar proved successful and they agreed on using it during the following missions. These technical issues may have also overlapped with other geopolitical concerns. The role of Denmark as a founding NATO member with sovereignty over Greenland, a key strategic territory in the US line of defence, may have instigated collaboration between the NSF and Danish scientific parties, first in the Arctic, then in the Antarctic. ${ }^{66}$

Oscilloscopes and cameras were essential to radar operations. During later missions they were used in combination with other visual and recording technologies that enhanced accuracy and visual rendering. Their use in RES operations was greatly beneficial because it allowed electronic imaging of the bottom topography. In the 1960s the leading company in oscilloscope manufacturing was the US firm Tektronix. Its cofounders Howard Vollum and Jack Murdock had pioneered the sector by inventing the first triggered oscilloscope in $1946 .{ }^{67}$ Its chief innovation was that it allowed the display of single pulses, which greatly enhanced RES operations. Moreover, the 321 model was advertised as 'for the travelling engineer'. Its weight, only nine kilograms, made it especially valuable for airborne sounding. ${ }^{68}$ The technique of attaching film cameras to oscilloscopes was not new. The firm D. Shackman \& Sons, based in Chesham in Buckinghamshire, had by then become popular as a producer of oscilloscope cameras such as the AC 2/25 model. It mounted a $35 \mathrm{~mm}$ film, which presented the oscilloscope output. The off-the-shelf camera was modified for continuous slow advance, and its advance speed could also be controlled through the SPRI Mark IV panel.

The very act of using radar apparatus during missions regimented operations. Even before the first mission Evans realized that the coordination of detection techniques and visual technologies was extremely important to the ultimate success of sounding operations. ${ }^{69}$ In the early years of RES, echo detection was intermittent

64 'Proposed SPRI/NSF RES Operations in Antarctica, Spring 1973', 'SPRI-Ice thickness', Box 30, NSF 307/64, NARA.

65 R. Zwally's note, 5 June 1973, in 'SPRI-Ice thickness', Box 30, NSF 307/64, NARA.

66 Thanks to one of the anonymous referees for highlighting this issue to us.

67 Marshall M. Lee, Winning with People: The First 40 Years of Tektronix, Beaverton, 1986.

68 Monitoring considerations dictated that Evans adopt a pulse radar system rather than a frequencymodulated one: 'A pulse radar system was chosen mainly for this reason, because the monitor output is immediately interpretable, whereas a frequency-modulated system would require a bulky multi-channel analyzer to present complicated output information in a similar form'. Evans and Smith, op. cit. (62), 135.

69 Evans's previous work in ionosphere research also played a role in this realization: 'We then realized that these ideas which had been developed generally in radar, and in my particular case the meteors, and a lot of ionospheric analysis - they could just be lifted straight in. It was very easy ... We have drawn a terrific lot of analogies, a lot of results from ionospheric work; fading patterns, movement, reflections from rough surfaces, propagation through irregular media, it is all very closely related to the ionospheric thing.' Mulkay, op. cit. (29), 219. 
and erratic. ${ }^{70}$ Fading patterns, scattering effects, noise and interference compromised detection and it took several years to make the technique reliable. Recording operations on camera film would start only when system performance was optimized. Improving performance meant finding the 'echo strengths', the points in which the signal-to-noise ratio (measured in decibels) of echoes allowed satisfactory detection. The operator would thus record in logbooks sweeping operations in an attempt to hit upon these echo strengths. Only at that point would the camera shutter be open to produce RES films. ${ }^{71}$

With its speed synchronization and signal control, the entire system needed calibration. For this purpose each mission would start with some trial flights at New Zealand's Christchurch airport to find out what signal attenuation would be ideal in registering echo strengths. During trial flights the apparatus was tested for this purpose on a horizontal smooth reflector (calm sea or thin sea ice). From the fifth mission new instrumentation perfected this coordination. A fibre-optic recording oscillograph was produced by Honeywell, which allowed the printing of oscilloscope images during flights, whereas a new apparatus for the measurement of echo strengths was designed at the SPRI. ${ }^{72}$

\section{The airborne laboratory}

Aircraft were a major technological feature of each mission, affecting decision-making on weight of equipment, overall electric power, range, navigation and installations. The US Navy Squadron VX-6 provided SPRI personnel with the aircraft already deployed for transport of supplies. A Lockheed C121 Super Constellation was used during the first mission. This was a modified version of the commercial Constellation adapted to military duties by the US Navy. The C121 had a range of 3,380 kilometres, stretched for the RES mission to 3,800 kilometres by installing a special fuel bladder in the passenger cabin. ${ }^{73}$ From the second mission the US Navy made available one of its Lockheed C130s, which ensured greater reliability. In 1960 VX-6 had equipped its air fleet with six new Hercules C130 Fs, which became the chief aircraft for heavy transport deployment in Antarctica, also allowing short take-offs and landings. Model $\mathrm{F}$ was faster than the C121, allowing cruising at 355 miles per hour, and had virtually the same range as a

70 This is shown in the logbooks of the Greenland experiment. For example: 24 June 1964, 'bottom echoes obscured by scatter. Watch abandoned'; 'echo begins to merge ... no echo observed'. 28 June 1964, 'Complicated shallow region, very shallow echoes'. Similar remarks continued to appear in late logbooks and during all SPRI-NSF missions. See Greenland Logbooks, 1964, THMA.

71 The operator would record on logbook 'OS-open shutter'; 'CS-close shutter'. Logbooks of earlier operations show records of signal attenuation (expressed in $\mathrm{dB}$ ) as well as pulse rate (in $\mu$ s). Interestingly, the pulse rate would also be expressed in div. (divisions per second), showing again the importance of visual feedback from the oscilloscope. Division is each square of the lattice's graticule that appears on the oscilloscope. See Greenland experiments logbooks, 1964, and Ellesmere Island logbooks, 1966, THMA.

72 This also 'gave an invaluable boost to the enthusiasm of both aircrew and scientists, as well as providing data of the highest quality'. D. J. Drewry and D. T. Meldrum, 'Antarctic airborne radio echo sounding, 1977-1978', Polar Record (1978), 19, 267-73. On the echo-strength apparatus see C. S. Neal, 'Radio-echo power profiling', Journal of Glaciology (1976), 17, 527-30.

73 Anon., 'Radio echo exploration of the Antarctic ice sheet', Polar Record (1967), 14, 211-13. 
modified C121. Most missions demonstrated the advantages offered by the C130 F in terms of greater number of hours flown. In the last two missions a new model, the C130 $\mathrm{R}$, was introduced. This had an even greater range because of its under-wing external fuel tanks. ${ }^{74}$

Navigation technologies were also a crucial feature of these missions as it was essential that SPRI personnel knew the position of the aircraft during the whole flight in order to make valuable use of RES data. Just before the 1960s aircraft navigation technologies moved from dead reckoning to inertial navigation. ${ }^{75}$ Dead reckoning, used during the first two missions, was far from accurate and margins of error of between thirty and thirty-five kilometres were not uncommon, a major problem since Robin intended to produce a hundred-kilometre grid map survey of Antarctica. ${ }^{76}$ The SPRI personnel tried reducing these margins by using additional positional data through trimetrogon photography, which enabled their reduction to ten kilometres. ${ }^{77}$ Nonetheless, positional errors continued to affect surveying.

After the 1971-2 season, two Litton LTN-51 devices for inertial guidance were installed on the aircraft. Inertial navigation enabled the calculation of the position of the aircraft by measuring its linear and angular accelerations, all thanks to gyrocompasses. Inertial guidance had been developed chiefly for intercontinental and submarinelaunched ballistic missiles. But a number of American companies, including Litton, Honeywell, Sperry Rand, Autonetics and AC Delco, competed to pioneer the new technology, knowing its potential for the aircraft navigation market. ${ }^{78}$ Not only did the application of inertial guidance to RES missions greatly reduce the margin of error in positioning, now in the order of five kilometres (and usually between two and three kilometres), it also allowed for a complete change in mission planning and execution. Before and during the 1971-2 season, aircraft had to follow flight lines derived from McMurdo and another Antarctic base. The introduction of inertial navigation allowed the definition of flight lines according to grid patterns, regardless of arrival and departure points (Figure 5). ${ }^{79}$

74 Description of the new C130 for Antarctic exploration is given in 'Use of jet-prop aircraft at US Antarctic stations, 1960', Polar Record (1960), 10, 298. On performance during missions see Drewry and Meldrum, op. cit. (72), 268.

75 In dead reckoning navigation the aircraft position is estimated considering course (direction of travel), speed and distance of the aircraft at a certain moment in time during travel.

76 G. Robin, D. Drewry and D. Meldrum, 'International studies of ice sheet and bedrock', Philosophical Transactions of the Royal Society of London (1977), 279, 185-96.

77 D. Drewry, 'RES map of Antarctica', Polar Record (1975), 17, 359-60. This was obtained through the use of three cameras placed on the same frame, but at different angles. The SPRI archive still has cameras that were very probably used during these missions, one a large Zeiss Ikon camera made in Germany, the other the K20 model produced by the Fomer Graflex Corp for the US Air Force, normally used in reconnaissance operations. On the importance of photogrammetry see Cloud, op. cit. (8), 263.

78 Litton was a start-up company that 'played a major part in the development ... and became AC Delco's original main competitor in the civil air market'. D. Mackenzie, Inventing Accuracy: A Historical Sociology of Nuclear Missile Guidance, Cambridge, MA, 1990, 174.

79 Drewry, op. cit. (77). 

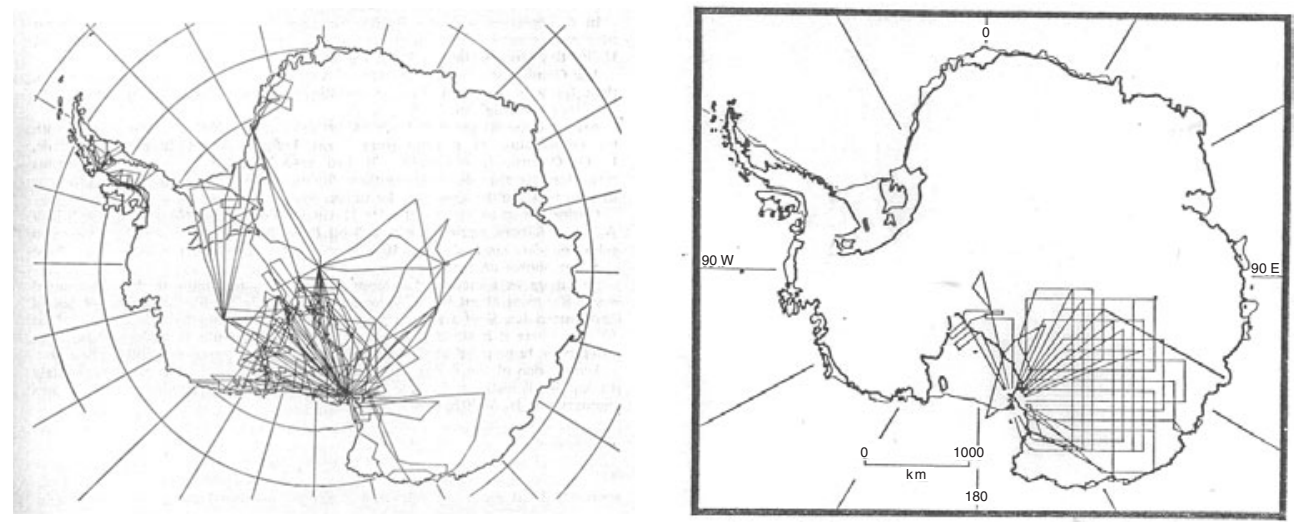

Figure 5. Charts illustrating the flight lines used during RES missions before (1969-70) and after (1971-2) the introduction of inertial navigation. The new navigation system allowed the gathering of data on Antarctica's ice thickness and bedrock morphology on a 'grid' pattern, which in turn made it easier to process data and compile maps. The first chart is from S. Evans and B. Smith, 'Radio echo exploration of the Antarctic ice sheet, 1969-1970', Polar Record (1970), 15, 336-8; the second is from S. Evans, D. Drewry and G. Robin, 'RES in Antarctica, 1971-1972', Polar Record (1972), 16, 207-12.

Navigational data were so essential to airborne missions that the SPRI crew had to develop a way of making them immediately accessible. ${ }^{80}$ When in 1966 the Mark II apparatus was flown first at Ellesmere Island then on the Antarctic Peninsula, the correlation of positional and ice-thickness data was ensured by using flight recorders of the SFIM type. ${ }^{81}$ Flight recorders (or 'black boxes') were introduced in the late 1950s for the purpose of indicating flight parameters, especially in case of accident. The use of SFIM for RES data-gathering was possibly due to Charles Swithinbank, who used the flight recorder during the BAS airborne mission of 1966-7. ${ }^{82}$ In land-based missions such as the Greenland experiments the experimenter would take records of position and RES apparatus performance data in the same logbook. However, with the beginning of airborne operations, it became necessary to review these procedures, and deal with navigational and RES data separately. During the trials in Canada Evans had taken responsibility for recording the data on RES apparatus performance in one logbook, whereas Robin filled another with navigational data. ${ }^{83}$ In this way they pioneered the procedure later adopted in most missions, whereby SPRI personnel filled a 'glaciologist's' logbook containing

80 On land carriers such as the Polecat, an odometer was sufficient for linking position and vertical measurements. See J. T. Bailey logbooks, 1965, THMA.

81 Produced by the French Société de fabrication d'instruments de mesure (SFIM, now SAGEM).

82 The correlation with the aircraft navigation system was provided by an SFIM using a 60 mm photographic paper, which carried altitude, temperature, heading and terrain-clearance traces. Anon., op. cit. (73), 211.

83 Ellesmere Island logbooks, 1966, THMA. 
general data on navigation and a 'radio-echo' logbook containing data on the RES performance. ${ }^{84}$

Integration of radio engineering and avionics was also important, as shown by the case of antenna installation. The main priority for SPRI personnel was to use antenna-enhancing pulse detection in the receiver. But considerations of the antenna's impact on the aircraft were also important. Larger antennae allowed greater gain, but dangerously increased the drag on the aircraft. ${ }^{85}$ Antenna design was assigned to the SPRI only during the first mission, when the antenna was installed on the C121's tailplane. ${ }^{86}$ During the following mission antenna design was effectively the result of a collaborative effort between the SPRI and the aircraft producer, Lockheed Corporation, as well as the aeronautics engineers at the US Naval Air Development Center based in Warminster, Pennsylvania. ${ }^{87}$ Later, the antenna design was assigned to Gudmansen. He developed new 'butterfly-plan multi-wire dipoles' which had weaknesses in design but allowed a significant power gain. ${ }^{88}$

From the fourth mission the TUD effectively became responsible for the design and construction of the RES apparatus as well as the antenna design. This left the SPRI to concentrate on the applications of the equipment to glaciological problems, confirming their role as the scientific centre of the collaboration supported by NSF funding, US Navy logistical support and TUD technical support. As the TUD apparatus worked at two different frequencies it also needed two different aerial systems. The $60 \mathrm{MHz}$ antenna system was an array of four half-wave dipoles similar to those previously adopted. The new $300 \mathrm{MHz}$ antenna system used four dipoles of much smaller dimension. ${ }^{89}$ Although much changed in antenna design between 1967 and 1979, the forms of international and interdisciplinary collaborations between scientific and military research institutions continued to be of great importance.

In summary, the deployment of RES relied upon an efficient system, the NSF airborne laboratory, which embodied a number of technologies, of which RES apparatus was but one. The end result of technological integration was data integration. This was clearly shown by Drewry in a chart detailing how data-gathering on ice thickness was only one important aspect of RES missions (Figure 6). ${ }^{90}$

84 Still available for consultation are seventeen radio echo logs and thirteen glaciologists logs for the second mission (1969-70); six radio echo logs and ten glaciologists logs for the third mission; twenty-five glaciologists logs, three TUD panel logs; eight SPRI panel logs for the fourth mission, 1974-5, THMA.

85 Petrie was instrumental in suggesting the use of terminated dipoles rather than half-wave dipoles. On antenna drag see Laurence Burke, 'Radar aboard aircraft', in Encyclopedia of 20th-Century Technology (ed.

C. A. Hempstead and W. A. Worthington, Jr), New York and London, 2004, 621-3, 621.

86 Anon., op. cit. (40), 212.

87 S. Evans and B. Smith, 'Radio echo exploration of the Antarctic ice sheet, 1969-1970', Polar Record (1970), 15, 336-8.

88 Evans, Drewry and Robin, op. cit. (60).

89 See Drewry and Meldrum, op. cit. (72).

90 On data integration see K. Dean, S. Naylor, S. Turchetti and M. Siegert, 'Data in Antarctic science and politics', forthcoming in Social Studies of Science. 
NAVIGATION

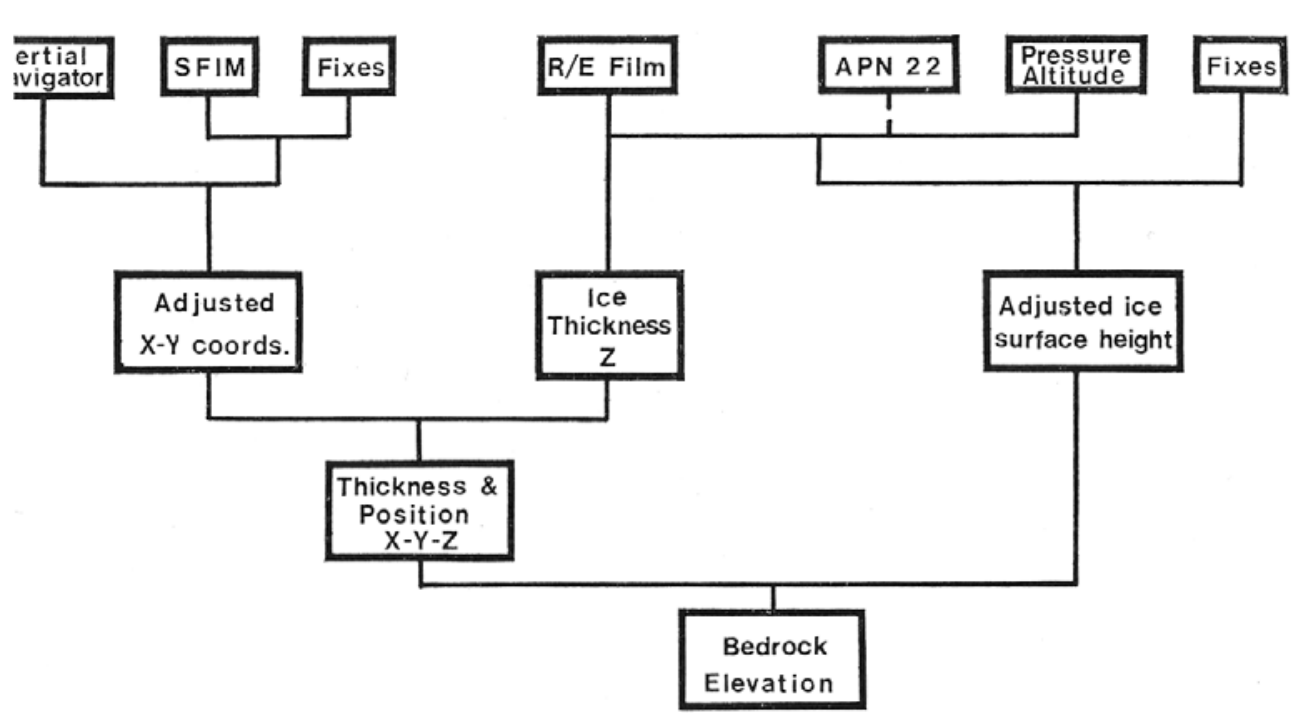

Figure 6. Drewry's flow chart. From D. Drewry, 'RES map of Antarctica', Polar Record (1975), 17,362 .

\section{Not just serendipity}

The history of RES demonstrates that serendipity can play a vital part in science in general as well as in twentieth-century big science more specifically. Amory Waite's and Stanley Evans's understanding of the electromagnetic properties of ice derived from accidental discoveries in research areas that had nothing to do with glaciology. Yet the realization that Waite's and Evans's instruments could be readapted to glaciological research followed an investigation of the errors marring the functioning of their apparatus. Waite developed RES whilst examining altimetry errors experienced by pilots flying over Antarctica, while Evans understood the potential of RES while solving interference problems affecting ionosphere research. So it was the study of experimental errors that led to scientific and technological innovation. Using serendipity as an explanatory framework therefore helps us to understand the transition from glaciology to radio-glaciology, in that the examination of error analysis was the cornerstone of the origins of RES.

This paper has also shown that full realization of RES's potential depended on changing Antarctic geopolitics. If the early work of Evans and Waite later bore fruit, it was chiefly because new political circumstances in Cold War Antarctica helped the likes of Gordon Robin and Albert Crary to establish new forms of international patronage for glaciological research. Political influence played a key role in transforming accidental scientific findings into large-scale research endeavour. The Antarctic Treaty let (wealthy) nations participate in SCAR and develop research programmes on the 
continent, while new Cold War circumstances encouraged nations such as the USA to support Antarctic science at an unprecedented level after the IGY ${ }^{91}$ Glaciologists with key roles in the administration of Antarctic affairs exploited these circumstances to promote the development of RES, to test its efficiency and to plan large-scale research in Antarctica based on the deployment of RES technologies. These opportunities sparked scientific competition as well as international collaboration between glaciological groups in Britain, the US and the USSR and ultimately led to the setting up of the joint SPRI-NSF missions. Moreover, from the IGY onwards a new vision permeated US science policy: that it would be highly beneficial, from both a propagandistic and a utilitarian point of view, to design new frontier research as collaborative and international. ${ }^{92}$

It is also for this reason that during the RES missions glaciologists could count on the support of military organizations such as the US Navy. Circumstances after the IGY made it politically and strategically sound for the US military to aid scientific research in Antarctica on a large scale. The US Navy did already have a significant presence in Antarctica and had previously been interested in polar scientific exploration. It was in fact Operation Highjump that marked the beginning of military influence on Antarctic exploration and research. Yet the new political circumstances defined by the Antarctic Treaty demanded greater involvement of the US Navy in Antarctic scientific affairs and the logistical support of research initiatives on a larger scale.

It is because of the scale of the British-American-Danish effort that our coverage of the history of RES in Antarctica is centred on the NSF-funded research initiative. This was the only project in which long-range aircraft were deployed and the only one aimed at covering the entire continent. But this was by no means the only attempt successfully to use RES in Antarctica. In 1969 a Belgian team led by glaciologist Tony van Autenboer used RES instrumentation installed on a Otter plane in the context of a joint Belgian-South African project. This was, however, short-lived due to Belgian opposition to the apartheid regime, which thwarted future collaboration. ${ }^{93}$ An Australian team also deployed ground-based and airborne RES in the context of explorations of the Lambert Glacier Basin between 1968 and 1974. Finally, between 1967 and 1979 the Russians continued to use their RES apparatus in the context of the Soviet Antarctic expeditions. It is also worth noting that after the end of the SPRI-NSF collaboration, many different small-scale RES projects have provided a more detailed picture of the glaciological and geophysical structures of Antarctica and that these projects continue now. ${ }^{94}$

91 See S. Naylor, M. Siegert, K. Dean and S. Turchetti, 'Science, geopolitics and the governance of Antarctica', Nature Geosciences (2008), 1, 143-5.

92 Korsmo, op. cit. (33).

93 A. Enzinga, 'Geopolitics, science and internationalism during and after the IGY', 2nd Workshop of the SCAR Action Group on the History of Antarctic Research, Santiago, 21-2 September 2006.

94 Recent airborne RES projects in Antarctica have been discussed by F. Ferraccioli and J. W. Holt in the context of the 'Post-international polar year: geophysical exploration of Antarctica' session during the American Geophysical Union fall meeting, 11-15 December 2006. 
Antarctic big science also won military support because of potential strategic uses that this paper has only investigated to a limited extent. The 'airborne laboratory' was a new concept put forward within the NSF to unite basic science surveys and reconnaissance in Antarctica. For example, the use of photogrammetry was essential to both. ${ }^{95}$ The military potential of RES also did not go unnoticed. In fact SPRI and TUD personnel were asked to develop new RES systems to spot Vietnamese forces hiding in the jungle, a proposal they promptly refused..$^{96}$ Apart from the technique, maps offered important data for future explorations. Drewry's final publication was funded through important British and US oil concerns, possibly with a view to the potential value of Antarctica's natural resources, following a decade in which oil and other resource exploration had been one of the preoccupations of the Antarctic Treaty Organisation. ${ }^{97}$ In the history of RES, scientific, military and industrial concerns were soldered together.

Political and strategic urgencies moved RES from a state of contingency to one of planning. Technological needs defined the final phase of RES's deployment, typified by military-style campaigns in which errors were reduced to a minimum. RES had become part of a complex technological system relying upon a number of components whose functioning had to be coordinated, integrated and synchronized. Yet technological integration may also have been the cause of the termination of the RES missions in 1979 . Despite there being forty per cent of the land mass still to survey, the NSF took the decision to end their support for the project, a decision partly due to a data-handling policy at the SPRI that did not suit American science managers. ${ }^{98}$ Changing priorities and new technologies also played a part: Antarctic exploration was no longer considered as important as, for example, remote sensing through satellites. ${ }^{99}$ Finally, the complex technological system set up in the 1960s had begun to show cracks. The last two missions were not successfully completed and a number of problems made it impossible to fly the amount of hours originally planned. ${ }^{100}$ These problems had highlighted the fact that growing complexity and integration also augmented the system's unreliability. If one of its parts were faulty the whole system could be affected. The last mission completed only less than fifty per cent of planned flying hours. ${ }^{101}$

95 Cloud and Clarke, op. cit. (8), 261-82. See also J. Cloud, 'Imaging the world in a barrel: CORONA and the clandestine convergence of the earth sciences', Social Studies of Science (2001), 31, 231-51.

96 Interview with Dr C. Swithinbank in Cambridge, UK, 2 June 2004. The plausibility of such potential developments of RES was confirmed by the fact that Evans later went on to develop soil-sounding techniques for application to archaeological research.

97 Dean et al., op. cit. (90), 19.

98 Dean et al., op. cit. (90), 15-17.

99 'Exploration is no longer the prime attraction in Antarctic research. Modern satellite photography provides a wealth of geographical and physical details on an almost routine basis. The contemporary thrust of Antarctic research is toward examination of significant phenomena for a more comprehensive understanding of the polar environment in context with global natural and physical problems.' 'NSF Science Operation Plan, 1977-1982', in 'Long Range Plans', Box 1, NSF 307/93, NARA.

100 Amongst the problems experienced during the sixth mission there was a cracked tyre, damage to the port of one external fuel tank that reduced fuel capacity, and problems with one generator that affected the performance and functioning of electronic apparatus deployed on the aircraft. See D. J. Drewry, D. T. Meldrum and E. Jankowski, 'Radio echo and magnetic sounding of the Antarctic ice scheet, 1978-1979', Polar Record (1980), 20, 43-57.

101 In $1977-8$ only 141 hours of 450 planned were flown. 
In conclusion, as one compelling example of big science in Antarctica, the RES programme began and ended with accidents and demonstrated that accidents can work as windows of opportunity for scientific research, allowing their actors to explore freely alternative uses of instrumentation. But in the case of RES the exploitation of these opportunities relied upon much more than the investigators' sagacity. It depended on mastery of international scientific and political relations to create interest in newly found scientific methods and technological tools. As shown by the activities of Robin and Crary, scientific administration was fundamental in achieving the genuine viability of enterprises until then merely foreseen through a set of accidental discoveries. In turn, the administration of large-scale technological networks was equally decisive in changing freewheeling scientific activities into structured data-gathering processes defined by precision and accuracy. 